\title{
Ciudadanía, derechos multiculturales y democracia liberal
}

"Vamos a darnos cuenta de que, herederos de la era de la llustración, somos herederos amnésicos: las leyes se han convertido en recetas, el derecho en un método, y los Estados-Naciones en espacios juridicos. ¿Es suficiente para asegurar el futuro de la idea democrática? Hay que preguntarse hoy si puede existir una democracia sin nación. El gran edificio de la era institucional ha perdido sus conocimientos y flota, libre de toda amarra, abandonado a si mismo..."

Jean-Marie Guéhenno

\section{Introducción}

Quizá nunca como ahora el debate filosófico-político del mundo anglosajón había mostrado una vitalidad, un desarrollo y una influencia tan decisiva para pensar los graves desafíos de fin de siglo que aparecen en el plano de la reflexión en tomo al funcionamiento y los mecanismos de constitución de la moderna convivencia social y política. Al respecto, puede reseñarse la existencia indiscutible de una sumamente abundante teoría liberal producida en las últimas décadas del presente siglo. Ello ha provocado un poderoso renacimiento del pensamiento liberal que una vez más vuelve a ocuparse de sus temas clásicos y preferidos tales como los aglutinados en los enfoques (neo) contractuales para rápidamente evolucionàr hacia el desarrollo de nuevas cuestiones -igualmente candentes pero quizá más desconcertantes- con contenidos de reflexión inéditos como el multiculturalismo, las identidades nacionales, el Estado Postnacional, el feminismo, etc.

Admito que el anterior párrafo con el que inicio las presentes reflexiones fragmentarias peca de un cierto entusiasmo excesivo. Cabe destacar, efecto, que 
el tono de los múltiples diagnósticos de los filósofos políticos profesionales sobre los desafíos del presente suelen ser si bien no del todo pesimista si quedan marcados bondamente por la complejidad de la realidad actual caracterizada por las inesperadas mutaciones registradas en las principales instituciones, ámbitos y referentes del terreno de la organización de la coexistencia pública y democrática, la cual, por lo demás, siempre ha estado acompañada de una luminosa aura de incertidumbre. Pero una vez reconocido lo anterior, no puede negarse que la amplia agenda que configura la base sustantiva para una discusión seria, sistemática y fundamental en torno a los elementos involucrados en la definición de un cuerpo-de principios organizadores de la convivencia social, la solidaridad y la concepción misma de los derechos tanto individuales como sociales correspondientes a un nexo social óptimo se encuentran hoy día en el interior de las diversas variantes del pensamiento liberal.

Ejemplos relevantes de los puntos que constituyen esa agenda son, precisamente, la reflexión respecto a las nuevas condiciones del pluralismo, la redefinición de la esfera pública, las cuestiones relacionadas con la emergencia de nuevas identiđădes nacionales y el multiculturalismo, el replanteamiento de la idea de ciudadanía y el consecuente replanteamiento de los derechos y deberes que acompañan a dicha concepción, los nuevos dinamismos de las instituciones básicas de la modernidad como son el Estado y el mercado, el replanteamiento de lo que debe entenderse por una sociédad justa, etc. En suma, pues, la discusión política sustantiva de fin de siglo se encuentra dominada por el pensamiento filosófico liberal. Ello es así, claro esta, no en el sentido de que la filosofía liberal pretenda ser o se haya convertido en los hechos en un pensamiento "único" o "hegemónico", sino más bien en el sentido de que aunque muchas otras escuelas, corrientes o tradiciones de pensamiento - por ejemplo, el neoconservadurismo, el postmodernismo o la teoría crítica- no estén de acuerdo con los dictados del pensamiento liberal la definición de su propia postura —en relación a los demás capitales del fin de siglo-suele estar sobredeterminada o definida en oposición, justamente, al pensamiento liberal.

Ahora bien, si tuviese que sistematizar ese amplísimo panorama de temas y problemáticas alrededor de una polémica o reflexión concreta me atrevería a sostener que el conjunto de cuestiones desarrolladas por el pensamiento liberal pueden agruparse en torno a tres ejes centrales de desarrollo, a saber: el debate liberalismo-comunitarismo; la discusión sobre la emergencia de nuevas identidades nacionales, es decir, la amplia temática del multiculturalismo; y, finalmente, la relación entre liberalismo y democracia en el contexto del nuevo horizonte de fin de siglo. Ninguno de esos tres ejes de desarrollo ha sido agotado de manera concluyente. De ellos, el primero, el debate entre liberales y comunitaristas en relación al tema de la justicia, es el que ha suscitado un amplio y candente debate que a pesar de haber generado importantes consensos en relación a sus principales tópicos de discusión todavía sigue abierto y actual, si bien con menor fuerza. 
El segundo eje de desarrollo, esto es, la reflexión en torno a la problemática abierta por el multiculturalismo, es el que me parece ocupa el primerísimo lugar de interés en la agenda filosófica liberal de hoy día. Por tanto, es un tema no sólo actual y vivo sino fundamentalmente inacabado en su planteamiento, abordaje y resolución.

Finalmente, el tema de la relación entre liberalismo y democracia es, al parecer, el que espera su turno para quizá englobar y capitalizar el resultado de los dos debates procedentes. A mi me parece que decir alegre y rápidamente - como hace Giovanni Sartori- que el colapso del socialismo real significa que la democracia como principio de legitimidad política se ha impuesto contundentemente y que, también, democracia es únicamente democracia liberal sin más es eludir un importante y crucial debate de nuestra época.

En efecto, es bastante evidente y común hablar de la honda y diversa crisis por la que atraviesan el conjunto de instituciones y prácticas, de reglas y procedimientos que constituyen el actual orden democrático. En concreto, lo que está en crisis es la concepción de todo el engranaje que articula la convivencia social. Es decir, el Estado, el mercado, la separación de poderes, la elección ciudadana de gobernantes - con todos los procedimientos e instituciones como los partidos políticos y la participación que la sustentan-, etc. De hecho, personalmente me impresiona el serio esfuerzo del pensamiento liberal (reconocimiento que no implica adherirme al liberalismo acrítica y totalmente) por enfrentar dicha crisis -que es, como digo, profunda y global- a través del planteamiento de una discusión normativo-analítica (forzosamente abstracta) que busca encontrar soluciones y opciones de salida a la perdida de eficacia de esas instituciones rebasadas por las complejas mutaciones postmodernas de fin de siglo.

En definitiva, más que una introducción he querido esbozar mi particular forma de ver el contexto general en el que se mueve el debate multicultural de hoy día. A continuación quiero volver sobre el tema del multiculturalismo, tocando en esta ocasión los desafíos abiertos por las presiones globalizadoras hacia el Estado-nación y, por otra parte, la nueva y ampliada manera de comprender el alcance y las dimensiones de la ciudadanía desde los retos que suponen la emergencia de las identidades multiculturales. Esta de más que recuerdo que no pretendo agotar ambas temáticas sino solamente trazar las líneas generales por donde transitan los principales argumentos relacionados con su tratamiento y discusión.

\section{Nacionalismo y globalización.}

El núcleo del problema que aquí intentare plantear es básicamente conocido y aceptado. También es un problema que cada vez se documenta más y que se encuentra acaparando agresivamente la atención de los estudios de la sociedad, la economía y la cultura. Por lo que a estas líneas respecta, el abordaje del 
problema puede formularse sucintamente de la manera siguiente: el Estadonación se encuentra sometido a dos tipos centrípetos de presiones poderosas desarticuladoras de su misma esencia. Por un lado, la emergencia de identidades étnicas que reniegan de su inclusión - frecuentemente injusta y desigual- dentro de una identidad nacional de corte abstracto-universalista. Se trata, pues, de una presión fragmentadora al interior de la unidad mayor del Estado-nación que, ante todo, implica una revisión de la idea y función del ciudadano dentro de un orden democrático universal.

Por otra parte, y de forma casualmente simultánea en el tiempo, el Estadonación también sufre fuertes presiones globalizadoras que rompen o tienden a romper igualmente su unidad nacional en favor de instituciones suprarregionales que atacan, a su vez, el corazón del Estado-nación como ente monopolizador de la soberanía territorial.

Pero para entender con mayor precisión y claridad los factores involucrados en esta doble tendencia desarticuladora del Estado-nación conviene ir por pasos acotados. Lo primero que hay que decir, en este sentido, es que el Estado-nación ha sido desde la consolidación del proyecto de la modernidad (siglo XVI) el principal marco institucional para regular — por lo general de manera desigual pero igualmente de forma relativamente estable y eficiente- las relaciones recíprocas de comunicación y/o sobredeterminación a todo nivel (política, comercio, etc.) de los pueblos y naciones del orbe.

El Estado-nación ha cumplido, en consecuencia, con la tarea de configurar una comunidad "homogénea" dentro de un definido escenario territorial bajo la guía de un ordenamiento sociopolítico centralizado. El Estado-nación ha pretendido ser, y en muchos casos lo ha sido, un cuerpo político unitario que se abrogó el derecho a ejercer una "soberanía" colectiva por medio de estructuras "nacionales" que mantenían el orden social, centralizaban y "universalizaban" la educación y unificaban la cultura. Todo ello en función, como nos explica E. Gellner, de crear y mantener activo un modo de producción sobre el cual las sociedades nacionales en su conjunto se basaban.

Por su propia naturaleza, en consecuencia, el Estado-nación pasó a convertirse en un espacio político en que gradualmente nació y consolidó la democracia como régimen político. Su pilar fundamental sería, ciertamente, la creación de la ciudadanía. Esto es, la creación de una poderosa ficción "igualitaria" que convertiría paulatina y extensivamente a los súbditos del antiguo orden feudal en ciudadanos miembros iguales y plenos de la sociedad nacional. $\mathrm{O}$, lo que es igual, en sujetos jurídicos, titulares de derechos y sometidos a obligaciones, como señalo, en un espacio con fronteras territoriales precisas. Con la creación de la ciudadanía, en realidad, el Estado-nacional ganó en integración social y en legitimación de su forma de dominación ya que: 
"Del Estado territorial surge el Estado constitucional democrático, es decir, un orden que, por su propia idea, es un orden querido por el pueblo y legitimado por una formación democrática de la voluntad, un orden, pues, en el que los destinatarios del derecho pueden entenderse a la vez como autores de él".

He aquí en suma, a través de una muy breve y apretada descripción la esencia del Estado-nación comprendido como síntesis y forma moderna de la soberanía y la ciudadanía.

Ahora bien, por muchas razones, algunas de las cuales exploramos a continuación, ese esquema anterior es ya ahora obsoleto e insostenible. En concreto, el Estado-nación se encuentra sometido, como ya adelantaba breves líneas arriba, de manera creciente a fuertes e ineludibles presiones de carácter supranacional de integración que la vacían tanto de contenido como de sentido aglutinador y organizador. En efecto, desde el siglo XIX, sin duda alguna, la humanidad, con la civilización occidental a la cabeza, ha experimentado sucesivas y cada vez más prolongadas y profundas "olas" de globalización e interdependencia de las actividades humanas más diversas (negocios, producción, comunicaciones, etc.)

Con el advenimiento de la tecnología puesta al servicio de la producción y con su tremendo impacto que virtualmente rompe con las limitaciones espaciotemporales el nivel de integración que representa el Estado-nacional va perdiendo importancia crecientemente en todas partes. En efecto, para mostrar con un ejemplo la perdida de capacidad de actuar y fijar los términos y los límites de una de las funciones primordiales del Estado-nacional cabe recordar como bajo el influjo del proceso de mundialización, el proceso productivo (sobre todo el industrial) se desnacionaliza y los mercados financieros se globalizan haciendo que las políticas económicas nacionales pierdan su capacidad de actuación.

Dicho de otra manera, el Estado-nacional no es hoy ningún lugar de retorno, sino un tipo de organización cuyo carácter problemático se vuelve cada día más hondo y visible. Y, por tanto, él mismo se constituye en sólo un punto de partida, hacia en nuevo tipo de organización política cuyo contorno aún no es del todo claro y definido. Las graves implicaciones y desafíos práctico-políticos específicos que ya se derivan de lo anterior tampoco se encuentran del todo claros ni son previsibles con cierta exactitud el curso que tome este proceso de debilitamiento del Estado-nacional. Para J. Habermas, a quién por supuesto no se puede acusar de ser un pensador «liberal», el panorama que se presenta es el siguiente:

"Las diversas tendencias a la globalización del tráfico, de los contactos y de las comunicaciones, de la producción económica y de su financiación, de la transferencia, en tecnologías y armamentos, del comercio de drogas y de la criminalidad, y, sobre todo, de los peligros tanto estratégicos como ecológicos, 
nos confrontan con problemas que ya no pueden solucionarse dentro del marco del Estado-nacional. El vaciamiento de la soberanía del Estado-nacional seguirá ahondándose $\mathrm{y}$, por tanto, resulta imprescindible proseguir con la ampliación de las facultades de acción política a nivel supranacional.

Como insisto, aún se encuentran en una etapa germinal todos los intentos por establecer capacidades supranacionales de acción mientras que los problemas globales crecen y amenazan con volver todavía más frágil e incierto el actual ordenamiento mundial. Dejando abierta, en consecuencia la reflexión sobre el anterior tópico, paso a examinar la problemática vinculada con la cuestión de la evolución de la idea y realidad fáctica de la ciudadanía en el contexto del presente fin de siglo.

\section{Ciudadanía multicultural}

En su conocido ensayo "Conciencia histórica e identidad postradicional", J. Habermas ofrece una interesante reflexión sobre el franco desafío que supone el debilitamiento de la ciudadanía a partir de las reivindicaciones étnicas y postnacionales de clara impronta particularista. Obviamente el análisis de Habermas toma como referente inmediato a la experiencia, ciertamente peculiar en el contexto de la Europa Central, de su natal Alemania. En este sentido, el autor se esfuerza por argumentar que la unidad nacional es deudora, como fuerza cohesionadora en torno a un cuerpo político, más de factores de corte cultural que de instituciones y procedimientos abstractos. Es decir, el carácter penetrante e integrador de la identidad nacional le debe más a una herencia cultural específica - manifestada en un lenguaje común, una historia y una literatura- que la forma de organización que representa el Estado más allá de toda la carga de integración implícita que esta forma política busca y posee. En la formación de la identidad colectiva nacional operan, por tanto, dos elementos - cultura y Estado- con pesos relativos dispares que en las condiciones de fin de siglo han sufrido un fuerte desplazamiento con un evidente impacto disociador. Al respecto, dice Habermas:

"Con esta desconexión de la identidad cultural común respecto de la forma de sociedad y de la forma de Estado, una nacionalidad que se ha vuelto ciertamente más difusa se disocia de la pertenencia a un Estado y deja sitio libre para la identificación con aquello que en la evolución de postguerra de cada uno de los dos Estados (se refiere a las dos Alemanias) la población considera digno ${ }^{b}$ de conservarse."

Me parece claro que las radicales redefiniciones nacionales experimentadas con inusitada fuerza en el mismo corazón de Europa en el actual contexto de evolución política preocupan mucho a Habermas. Este cae en la cuenta que quizá nunca como hoy la tensión e incluso el conflicto -latente en sus orígenes y ahora virtualmente presente- entre los principios universales del ordenamien- 
to democrático y los - generalmente justos- reclamos particulares de preservación de una identidad comunitaria étnica o cultural han sido tan fuertes y potencialmente disgregadores como hoy.

La propuesta de solución a tal desafío desde la óptica de Habermas revela la condición de pensador racionalista ilustrado del autor. Es decir, Habermas a la hora de elegir buscar ante todo opciones para mantener la integridad y/o unidad puesta a prueba del Estado-nacional democrático. Por ello, el autor apela a la afirmación de un cierto "patriotismo de la constitución" que no sería otra cosa que la creación de factores que predispongan o tiendan a permitir que los ciudadanos se identifiquen más y mejor con el orden político y los principios constitucionales de un régimen democrático que con el trasfondo de un pasado entendido en términos de historia nacional. Sostiene, al respecto, Habermas:

“(El patriotismo constitucional)... sólo surge después que cultura y política estatal se han diferenciado más enérgicamente entre sí que en los Estadosnacionales de viejo cuño. En este caso las identificaciones con las formas de vida y tradiciones propias quedan recubiertas por un patriotismo que se ha vuelto más abstracto, que no se refiere ya al todo concreto de una nación, sino a procedimientos y a principios abstractos. Y éstos se refieren a su vez, a las condiciones de convergencia y comunicación de formas de vida diversas provistas de iguales derechos, coexistentes. La idea abstracta de universalización de la democracia y de los derechos humanos constituye la materia dura en que se refractan los rayos de las tradiciones nacionales - del lenguaje, la literatura y la historia- de la propia nación".

A diferencia de Habermas, el pensamiento liberal presenta una argumentación radicalmente diversa y, para mi forma de entender la problemática abierta por el debilitamiento de la ciudadanía, más sensible a la complejidad del desafío planteado. El representante del pensamiento liberal que ha presentado la propuesta más acabada para enfrentar la masiva emergencia de demandas etnoculturales en el mundo contemporáneo es Will Kymlicka.

En su reciente obra, Ciudadanía multicultural, Kymlicka argumenta sólidamente a favor de la concesión de derechos políticos especiales a grupos de minorías dentro de un determinado Estado-nacional democrático. Según Kymlicka reconocimiento de los derechos de minorías toda vez que se guarden los correctivos que impidan abusar de tales derechos para afirmar particularismos (nacionalismos y fundamentalismos) intolerantes y beligerantes. Para mi gusto la lucidez de este enfoquue estriba en reconocer, como plantea $\mathrm{Ch}$. Taylor, que la única manera de enfrentar los nuevos desafíos emanados de la evolución del fenómeno de la ciudadanía es aceptar que la integración social puede y debe darse a partir de la existencia de profundas diversidades las cuales, en virtud de su específica legitimidad, van a definir diversos mecanismos de integración social. En palabras de Kymlicka: 
"Resulta legítimo y, de hecho, indudable, complementar los derechos humanos tradicionales con los derechos de las minorías. En un Estado multicultural, una teoría de la justicia omniabarcadora incluirá tanto derechos universales asignados a los individuos independientes de su pertenencia de grupo, como determinados derechos diferenciados de grupo, es decir, un "estatus especial» para las culturas minoritarias"

Desde esta perspectiva, el desafío de la propuesta de Kymlicka consiste en "explicar como coexisten los derechos de las minorías con los derechos humanos, y también como los derechos de las minorías están limitados, a su vez, por los principios de libertad individual, democracia y justicia social".

\section{A modo de conclusión}

Para poner punto final a las reflexiones fragmentarias ya desarrolladas, más que un resumen conclusivo de las mismas quiero, en cambio, señalar como los desafíos abiertos por las nuevas formas de entender la ciudadanía trasladadas al contexto de América Latina adquieren otro perfil y, de hecho, apuntan hacia formas premodernas de abordar dicha problemática. No deja de ser sintomático que en América Latina este doble desafío de las presiones encontradas de la globalización y la emergencia de las particularidades en realidad sean reflexionadas más bien por politólogos comparatistas que por filósofos profesionales (liberales o no). De esta suerte, del impacto globalizador en la región se destaca sobre todo la fragmentación social a la que se da paso en virtud de la acentuación de la estructural y secular condición de pobreza que agobia a la gran mayoría de los habitantes del subcontinente. Por ello creo que en América Latina las bases de legitimación del ordenamiento democrático todavía enfrentan el reclamo de la exclusión más bien en términos socioeconómicos que político culturales. Naturalmente ello le da un carácter diferente a la discusión de los tópicos anteriores.

Por ejemplo, en la región, los politólogos aún no parecen alcanzar acuerdos específicos y más o menos perdurables en tomo a las condiciones concretas bajo las cuales las instituciones democráticas funcionan y se sostienen - es decir, son eficientes- Ahora bien, parece existir evidencia importante que indica que la dinámica de la estructura socioeconómica condiciona a la democracia en al menos dos dimensiones.

En primer lugar, condiciones extremas de desigualdad —de pobreza extensa y profunda - socavan seriamente y/o limitan el ejercicio de la ciudadanía. Ello inevitablemente es así debido a que el presupuesto de la igualdad formal que los procedimientos universalistas de la democracia demandan para su funcionamiento eficiente se estrellan con la presencia de una desigualdad real -no solo cultural sino fundamentalmente material expresada en términos de condiciones de vida - incapaz de ser remontada por los mecanismos simbólicos que echan a 
andar el engranaje de las instituciones democráticas. En palabras de Robert Dahl, al parecer en una etapa ya tardía de su pensamiento:

"Si la ganancia, la riqueza y la posición económica son también recursos políticos, y si estos recursos están distribuidos desigualmente, ¿cómo es posible que los ciudadanos seamos políticamente iguales? Y si los ciudadanos no pueden ser políticamente iguales ¿cómo hace la democracia para existir?”

Dicho de otra manera: aunque existen distintas maneras de concebir a la democracia, todas ellas, más allá de su mayor o menor elitismo, presuponen en la base de su construcción la existencia de una base amplia de «ciudadanos» que se identifican como iguales entre sí a pesar de sus inevitables diferencias. Tal igualdad emana de la visión filosófica liberal que da a los seres humanos un valor político homogéneo. Todos los seres humanos como miembros de un orden político de convivencia adquirimos la condición de ciudadanos; esto es de sujetos políticos con derechos y deberes uniformes (libertad de conciencia, de religión, de expresión, de tolerancia, etc.) destinados a garantizar que todos recibamos igual respeto e igual oportunidad de realización. Naturalmente, condiciones de pobreza absoluta y las grandes desigualdades —en ingresos y estatus, por ejemplo- rompen en el terreno de la práctica política concreta con esta forma de razonamiento político-filosófico. Tal y como lo señalan C. Offe y P. Schmitter:

"El principio de igualdad política, incorporado en la ciudadanía y en los derechos de participación, puede no implicar la promesa de la igualdad económica, pero sí supone la posibilidad de realizar esfuerzos colectivos significativos para corregir los errores del mercado garantizando un ingreso mínimo y la seguridad del individuo, así como para facilitar la adaptación de la mano de obra y del capital a las condiciones cambiantes de la producción y la distribución. Si las democracias liberales no pueden cumplir estas promesas durante un período prolongado y para grandes sectores de la ciudadanía, los principios constitutivos de la igualdad ciudadana y de la competencia política corren el riesgo de ser considerados inútiles".

En cambio, la cuestión de cómo los ciudadanos controlan a sus gobernantes es, por supuesto, también una cuestión de disposiciones institucionales específicas pero igualmente es un desafío que toca la esencia misma de la democracia como régimen político participativo.

Deben existir, pues, dentro de un régimen democrático estructuras e instituciones diseñadas específicamente para hacer a los gobiernos responsables frente a los ciudadanos. Pero, además, el ciudadano debe poseer todos los incentivos y el grado apropiado de información y de intensidad de cultura política para forzar igualmente que los gobiernos sean responsables ante sus electores.

En consecuencia, la ciudadanía ejercida de manera plena y responsable es una condición necesaria para hacer que los gobernantes influyan eficazmente en 
la conducción de la dinámica económica y, por tanto, en generar las condiciones políticas que persigan atenuar la desigualdad sin desmedro excesivo de la eficacia económica. Se trata, en efecto, de una de las principales paradojas de la democracia.

\section{Como también señala Przeworski:}

"La democracia es un sistema que garantiza derechos de ciudadanía a la mayoría de los individuos, pero que no genera de manera automática las condiciones sociales y económicas necesarias para un ejercicio efectivo de estos derechos. Por tanto, en la medida que las desigualdades sociales y económicas limitan el acceso al sistema político, incluso los mecanismos de responsabilidad bien ideado pueden terminar por no hacer más que perpetuar las relaciones de clase. Una participación generalizada, así como una mejor distribución de bienes para facilitar el ejercicio de la ciudadanía es, por consiguiente, necesario para que funcionen los mecanismos de responsabilidad".

\section{Referencias Bibliográficas}

J.M. Guéhenno, El fin de la democracia. La crisis política y las nuevas reglas del juego, Barcelona, Paidós, 1995.

J. Habermas, Más allá del Estado Nacional, Madrid, Trotta, 1997.

W. Kymlicka, Ciudadanía multicultural Una teoría liberal de los derechos de las minorías, Barcelona, Paidós, 1996.

P. Rosanvallon, La nueva cuestión social. Repensar el Estado providencia, Buenos Aires, Manantial, 1995.

Ch. Taylor, El multiculturalismo y "la política del reconocimiento", México, FCE, 1993. Samuel Huntington, Civilizaciones en conflicto, Nexos, núm. 229, enero de 1997.

Varios, Revista Internacional de Filosofia Politica, Madrid, núm 7, mayo, 1996.

Varios, Metapolítica, México, núm. 3, julio-septiembre, 1997.

\section{Notas}

1. Hace veinticinco años, en efecto, los temas dominantes en el terreno de la filosofía política liberal eran los relativos al significado del poder, la naturaleza de la ley, la soberanía, etc. Pero desde la aparición de la obra de John Rawls en 1971, Teoría de la Justicia dio inicio un intenso debate entre las diversas escuelas liberales que puso su acento en la reflexión de cuestiones relacionadas con los ideales de la justicia, la libertad y la comunidad, así cómo de aquellas instituciones y las respectivas medidas políticas encargadas de hacer efectivos dichos valores. Véase: W. Kymlicka, Filosofía política cọntemporánea. Una introducción, Barcelona, Ed. Arie, 1995. Sobre el remozamiento y revitalización del liberalismo también puede consultarse: J.G. Merquior, "Una panorámica del renacimiento de los liberalismos" o también su obra póstuma: Liberalismo viejo y nuevo, México, FCE, 1993.

2. Resulta obvio, por lo demás, reconocer que uno de los objetivos qục impulsa al renacimiento del pensamiento liberal consiste en mostrar como desde dicho marco conceptual es viable construir o aportar unas bases morales sólidas que permitan 
preferir los principios de la tradición liberal para organizar la convivencia social por sobre otros posibles. Como señala en este sentido Merquior: "Si el liberalismo, actualmente, ha pasado a la ofensiva en la producción teórica, cllo obedece al hecho de que su segundo gran adversario histórico, el socialismo, cstá lejos de tener las manos limpias y el corazón sin culpas. En la obscrvación de Ralf Danrendorf, el liberal raramente necesita avergonzarse de las realidades creadas en su nombre. O, cuando lo precisa le resta el consuclo de verificar que el iliberal de izquierda (como aún ayer el iliberal de derecha) posec mucho más esqueletos en su armario". J.G.: Merquior, "Una panorámica del..." op. cit.

3. En otra oportunidad he escrito al respecto: "Algunos puntos fundamentales de cse (consenso) -al que concurren naturalmente solamente las posturas moderadas de ambas tradiciones y muchas de ellas con claras reservas- scrían: A. La acción estatal interventora, a pesar de todas las objeciones que se le han formulado especialmente en tiempos recientes, sigue siendo considerada como la política adecuada para remediar las graves y estructurales desigualdades sociales. B. Aceptación compartida por ambas tradiciones del proceso democrático moderno. Asi, por una parte, nadic dentro de los comunitaristas moderados sostendrá que hay que renunciar a los modernos derechos liberales, ni al imperio de la ley ni a la tolerancia. Por su parte, los liberales moderados habrían de aceptar que es la democracia la fuerza social legítima de igualación. En concreto, sus instituciones básicas y los principios, normas y preceptos que regulan su funcionamiento. C. El deseo de formular las que serian las condiciones básicas para dialogar entre los miembros de una determinada sociedad. Es decir, repensar las fuentes mismas del consenso social y del ejercicio del poder en el marco de un horizonte común. Todo ello con el propósito de responder a las nuevas condiciones de convivencia propias de un mundo pluralmente valorativo". A. Sermeño, "Justicia social y democracia liberal en América Latina", Inćdito.

4. Sostiene Sartori: "La democracia ha vencido, y la democracia que ha vencido es la única democracia "real». que se haya realizado jamás sobre la tierra: la democracia liberal". Cf. G. Sartori, La democracia después del comunismo, Madrid, Alianza, 1993, p.16.

5. Claro que no falta quién diga que el esquema liberal para pensar la democracia sea un esquema inoperante que no explica nada y que, de paso, nicga la esencia de la política. Tomándome la libertad de no tomar posición al respecto en ese momento creo que es justamente lo que se debe discutir a afondo: la naturaleza de esa relación de liberalismo y democracia en el contexto del complejo fin de milenio.

6. Tal y como lo hice - si bien de manera breve y fragmentaria - en el primer ensayo escrito para esta materia que titule: "Nacionalismo, identidades culturales y democracia. Aproximación a uno de los debates teóricos centrales de la filosofía política de fin de siglo".

7. E. Gellner, Naciones y Nacionalismo, México, CNCA/Alianza, 1991. Para ampliar la visión de Gellner recomendamos la muy bien lograda sección de Perfiles filosóficopolíticos, dedicada justamente a revisitar la obra de E. Gellner, de la revista Metapolítica en su último número de julio-septiembre de 1997.

8. J. Habermas, Más allá del Estado Nacional, Madrid, Trotta, 1997, p.177

9. U. Pipitone, "Ciudades, naciones, regiones", en Metapolítica, núm. 3, julio-scptiembre de 1997, pp.383-390. 
10. Por esta misma tendencia hacia la globalización y a la perdida de fuerza y sentido del Estado-nación surge también otro flanco de investigación que se preocupa de evaluar la evolución y las consecuencias que la globalización generará en términos de conflicto de civilizaciones. Como advierte Samuel Huntington al respecto: "El contacto creciente entre las culturas, promovido por los viajes y los medios de comunicación, ha intensificado la conciencia de las diferencias que hay entre las civilizaciones. La modernización económica y el cambio social que guían y acompañan este contacto cada vez mayor entre las culturas, ha tendido también a separar a sus pueblos de sus tradicionales identidades locales, debilitando al estado como lo que fue durante la era postcolonial, la fuente primordial de esa identidad". S. Huntington, "Civilizaciones en conflicto", entrevista aparecida en Nexos, 229, enero de 1997, p.42. Para ampliar en torno a la tesis del choque de civilizaciones de Huntington y una crítica oportuna a la misma recomiendo el dossier de más reciente número de Metapolítica llamado efectivamente "el conflicto de las civilizaciones". Cf. Metapolítica, núm. 3, julio-septiembre de 1997, pp.341-406.

11. D. Held, Democracy and World Order...

12. J. Habermas, Más allá del.. op. cit. P. 175

13. J. Habermas, "Conciencia histórica de identidad postradicional", en... Madrid, Taurus, 19.

14. Ibid

15. Ibid

16. W. Kymlicka, Ciudadania Multicultural, Barcelona, Paidós, 1996

17. Taylor citado por Kymlicka y Norman en "Return of de Citizen: A survey of Recent Work on the Citizenship Theory", in Ronald Beiner (comp.), Theorizing Citizenship...

18. W. Kymlicka, Ciudadania... ob. Cit. P.19

19. Ibid

20. R. Dahl citado por G. Sartori. En G. Sartori, La democracia después... op. cit. En honor al rigor intelectual cabe advertir que Sartori recoge esta cita de Dahl para rebatir su punto de vista. Según Sartori las prácticas y los procedimientos de instituciones democráticas consolidadas por sí mismos serian capaces de remontar los obstáculos que surgen de la extrema desigualdad material de los integrantes de un régimen político democrático.

21. C. Offe y P. Schmitter, "Las paradojas y los dilemas de la democracia liberal", cn Revista Internacional de Filosofía Politica, 1995, núm. 6, p.12.

22. Como al respecto recapitula Przeworski: "lo que hace falta, en resumen, es un sistema de partidos claro con partidos estables, una oposición vigorosa, un sistema eficaz de controles y equilibrios, un nivel aceptable de información centrada en la actuación económica en general y mecanismos no electorales de control sobre ámbitos específicos de política o determinados órganos de gobicrno". A Przeworski, "Una mejor democracia, una mejor economia", en Etcétera, México, núm. 222, 1 de mayo de 1997, p. 24.

23. Ibid. p. 25 